\title{
Rate and Predictive Factors for Sustained Complete Response after Selective Transarterial Chemoembolization (TACE) in Patients with Hepatocellular Carcinoma
}

\author{
Kittipitch Bannangkoon ${ }^{1 *}$, Keerati Hongsakul ${ }^{1}$, Teeravut Tubtawee ${ }^{1}$, Edward \\ McNeil $^{2}$, Hutcha Sriplung ${ }^{2}$, Virasakdi Chongsuvivatwong ${ }^{2}$
}

\begin{abstract}
Background: To determine the effectiveness and performance of selective conventional transarterial chemoembolization (TACE) and analyze the potential predictive factors of sustained complete response (CR) for patients with hepatocellular carcinoma (HCC). Materials and Methods: Total of 52 patients with HCC (33 males, 19 females; mean age $64.0 \pm 9.6$ years) who underwent 81 sessions of selective TACE between November 2015 and March 2017 at Songklanagarind hospital were reviewed. The Kaplan-Meier method was used to describe CR rates at various time points. Univariate and multivariate logistic regression models were performed to determine the predictive factors for sustained CR at six months. Results: The CR rates after selective TACE at 1, 4, 6, 9 and 12 months were $87 \%, 81 \%, 62 \%, 40 \%$ and $31 \%$, respectively. Univariate and multivariate analyses demonstrated that alpha fetoprotein level $<100 \mathrm{ng} / \mathrm{ml}$, a tumor size in summation $\leq 30 \mathrm{~mm}, \leq 2$ sessions of selective TACE and unilobar involvement had a significantly higher odds of sustaining complete response at six months ( $\mathrm{p}=0.018,0.031,0.032$, and 0.044 , respectively). Conclusions: Selective TACE has a good therapeutic results and can sustained complete response in selected HCC patients. Serum AFP $\leq 100 \mathrm{ng} / \mathrm{ml}$, a few sessions of selective TACE, tumor size in summation $\leq 30 \mathrm{~mm}$ and unilobar involvement were favorable predictive factors for sustained complete response of HCC patients.
\end{abstract}

Keywords: Complete response- predictive factors- selective TACE- Hepatocellular carcinoma

Asian Pac J Cancer Prev, 19 (12), 3545-3550

\section{Introduction}

Hepatocellular carcinoma (HCC) is a common malignancy worldwide. It is more common in men than in women and also is the second leading cause of tumor-related deaths after lung cancer (Torre et al., 2015). The incidence of HCC is increasing worldwide due to rising prevalence of risk factors such as excessive alcohol consumption and dissemination of hepatitis $\mathrm{B}$ and $\mathrm{C}$ virus infections (Bosch et al., 1999). Patients with HCC often present at a late stage, resulting in little or no chance of cure (Llovet et al., 1999; Bruix and Llovet, 2002; Trinchet and Beaugrand, 1997; Bruix et al., 2001). Moreover, a high proportion of early stage patients relapse after receiving first-line treatment (Lencioni, 2012).

Conventional transarterial chemoembolization (TACE) is the standard treatment for patients with intermediate-stage $\mathrm{HCC}$, relatively preserved liver function, no cancer-related symptoms, absence of vascular invasion, and no extrahepatic metastasis (Llovet et al., 2008). The procedure precisely administers chemotherapeutic drugs and iodized oil (Lipiodol,
Guerbet) to the tumor and blocks the tumor-feeding arteries with gelatin sponge particles. This results in combined cytotoxic and ischemic effects on the tumor cells. Moreover, TACE has been widely performed for the treatment in unresectable HCC patients and also indicated in advanced-stage HCC with partial main portal vein thrombosis (Bruix and Sherman, 2011; Arii et al., 2010). Selective TACE with catheterization at the tumor-feeding subsegmental hepatic artery gives significantly lower local recurrent rate (Miyayama et al., 2007; Iwamoto et al., 2003), reduces total dose of iodized oil and minimizes liver toxicity (Matsui et al., 1993) compared to non-selective TACE.

Complete response by non-selective TACE was poor in former decade (Llovet et al., 2002) but rates later improved with selective TACE (Miyayama et al., 2007; Takayasu et al., 2001; Miyayama et al., 2009; Matsui et al., 2010). For middle income countries with larger tumor size and more limited resources, the effectiveness of selective TACE has never been documented. Complete response at the initial assessment was found to be a good predictor of overall survival among patients with inoperable HCC (Kim et al., 
2015). Few previous studies reported factors associated with complete response in patients with HCC treated by non-selective TACE (Jeong et al., 2017; Yamakado et al., 2012) and information from selective TACE was also lacking. The objective of this study was therefore to assess the effectiveness of selective TACE in terms of complete response rate in $\mathrm{HCC}$ patients, and to find predictive factors of sustained complete response at six months.

\section{Materials and Methods}

\section{Patient selection}

Approval to conduct this study was obtained from the institutional ethics committee (60-220-07-1). The study was carried out at Songklanagarind hospital, a tertiary care hospital in southern Thailand, where selective TACE was introduced in November 2015.

Diagnosis of HCC, we followed the American Association for the Study of Liver Diseases criteria (Bruix and Sherman, 2011). Liver lesions larger than $1 \mathrm{~cm}$ in diameter were evaluated by dynamic magnetic resonance imaging or multidetector computed tomography (MDCT) scan using contrast media. If the imaging appearance was typical of HCC, no further diagnostic procedure was attempted.

All patients underwent blood investigations including complete blood count, liver function test, coagulation test, viral markers of hepatitis $\mathrm{B}$ and $\mathrm{C}$ infection, and serum alpha-fetoprotein (AFP). The assessment of chronic liver disease was based on the Child-Pugh classification system (Pugh et al., 1973).

Patient inclusion criteria were as follows: (a) adult HCC patients with hepatic cirrhosis, (b) patients treated with selective TACE with catheterization at the subsegmental hepatic artery feeding the tumor, (c) tumor size $\leq 7 \mathrm{~cm}$, and (d) number of distinct tumor nodules $\leq 5$, (e) patient was ineligible for surgical resection or transplantation. Patients with extrahepatic metastasis, infiltrative tumors, and severe arterioportal shunt were excluded. We also excluded any patient who did not have any follow-up assessments performed at six months.

\section{Chemoembolization steps and techniques}

All eligible HCC patients were invited to receive selective conventional TACE (TACE), defined as catheterization at the subsegmental hepatic artery performed by two interventional radiologists through the transfemoral route. Superior mesenteric artery and celiac axis arteriogram were selective at the beginning of procedure using a $5 \mathrm{Fr}$ selective catheter (Cobra or MIK catheter) and a 0.035 -inch J-tip Terumo guidewire. We performed selective catheterization to the tumor feeding hepatic arteries or in extrahepatic collaterals as distal as possible in each tumor lesion using a microcatheter (A 1.98-Fr tip Asahi Masters Parkway Soft microcatheter from Asahi, a 2.0-Fr tip Progreat microcatheter from Terumo or a 2.4-Fr tip Renegrade STC microcatheter from Boston Scientific) with coaxial technique. We slowly administered the mixture of iodized oil; range 4-16 ml (Lipiodol, Guerbet), the doxorubicin hydrochloride; range 10-40 mg (Adriamycin, Pfizer) under real time monitoring on Digital Subtraction Angiography (Phillips AlluraClarity FD20). The amount of anticancer-in-oil-emulsion was determined by total tumor size and number of nodules. Subsequently, this feeding artery was embolized using gelatin sponge particles. We completed the procedure when the tumor feeding branch was completely obstructed and tumor staining from digital subtraction angiography completely disappeared.

\section{Outcome and imaging follow up}

All patients were followed-up after selective TACE with detailed clinical examination, blood chemistry, and imaging examination (dynamic magnetic resonance imaging or 4-phase contrast-enhanced computed tomography scan) one month after the initial procedure. If no definite evidence of residual tumor was shown, then imaging examination was performed at 3-month intervals thereafter. The decision to repeat the TACE procedure was based on tumor response, stage of the disease, and patient's tolerance.

Tumor response was defined according to modified Response Evaluation Criteria in Solid Tumors (mRECIST) guideline (Lencioni and Llovet, 2010). Complete response(CR) defined as disappearance of any intratumoral arterial enhancement in target lesions (Lencioni and Llovet, 2010). Tumor size in summation was defined as the sum of diameters of two target lesions in the liver.

Assessment of response was evaluated independently by two radiologists with thirteen and five years of experience, respectively and the final decisions were achieved by consensus. All measurements were performed using the electronic tools available at the workstation (i.e., calipers for size measurements and circular regions of interest for attenuation measurement).

TACE-related morbidity/mortality was defined as any complication (including death) within two weeks of each session of TACE.

\section{Statistical analysis}

Data analyses were performed using R software (version 3.3.3). Numerical data are presented descriptively using the central tendency (mean, median and mode) and a measure of dispersion (standard deviation and range).

The probability of achieving complete response was estimated using the Kaplan-Meier method. The overall complete response rates at 1, 4, 6, 9 and 12 months was determined.

The comparison of demographic data and clinical factors were initially assessed with univariate analysis. Subsequently, all variables having a $p$-value $\leq 0.2$ from the univariate analysis were entered into the initial multivariate logistic regression model.

\section{Results}

Between November 2015 and March 2017, 69 HCC patients undergoing selective TACE were identified. After exclusion criteria were applied, 52 patients with total 71 HCC nodules (mean diameter, $2.6 \mathrm{~cm} \pm 1.4$; range, 1.0-6.9 $\mathrm{cm}$; median diameter, $2.0 \mathrm{~cm}$ ) remained and were included in the analysis. Figure 1 shows a flow diagram of the study. 


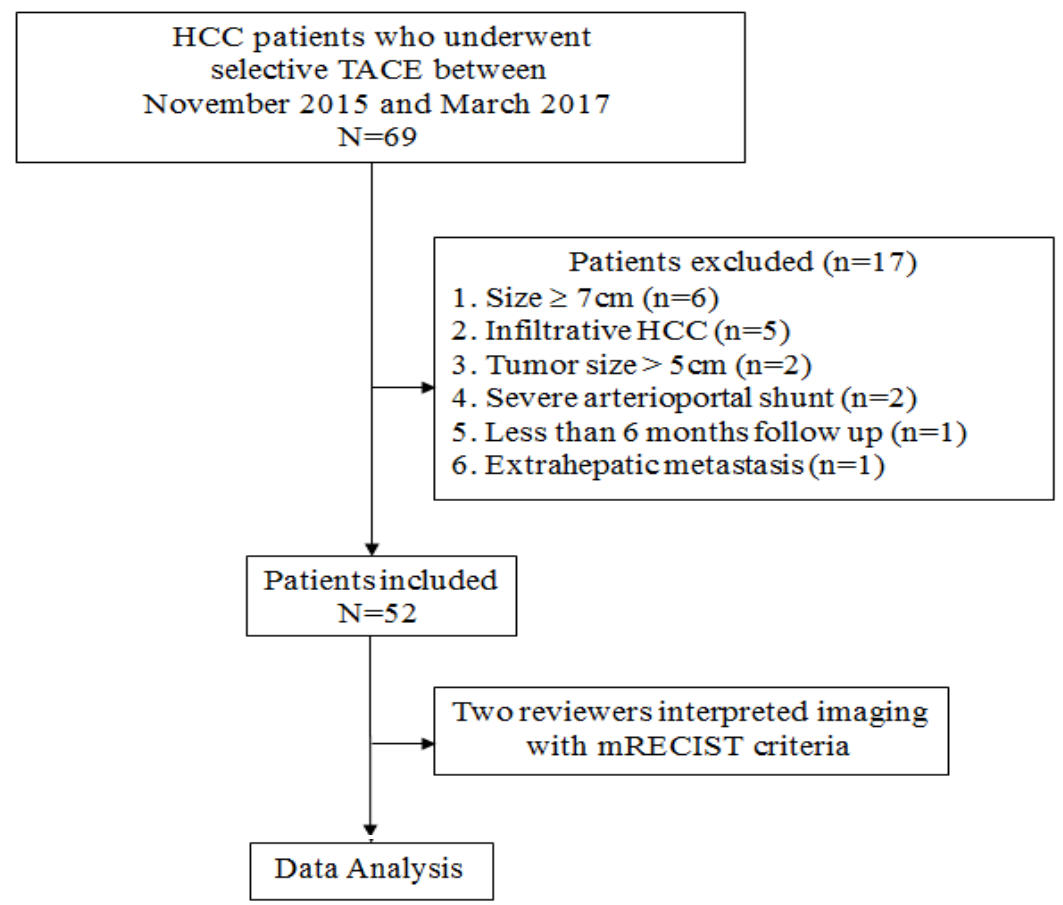

Figure 1. Flow Diagram of the Study. HCC, hepatocellular carcinoma; TACE, transarterial chemoembolization; mRECIST, modified Response Evaluation Criteria in Solid Tumors

A total of 17 patients were excluded due to tumor size $\geq$ $7 \mathrm{~cm}$ (6 patients), infiltrative HCC (5 patients), number of tumors $>5$ ( 2 patients), severe arterioportal shunt ( 2 patients), loss to follow up (1 patient) and presence of extrahepatic metastasis (1 patient).

A total of 81 sessions of selective TACE were performed (one session in 32 patients, two sessions in 15 patients, three sessions in 2 patients, four sessions in 2 patients, and five sessions in 1 patient). Demographic characteristics of the patients are shown in Table 1. There were 33 males and 19 females and the mean age was $64.0 \pm 9.6$ years (range 41-90 years). Hepatitis B viral infection (HBV) was found in $29(55.8 \%)$ patients. The numbers of patients with Child Pugh classes A and B were $42(80.8 \%)$ and $10(19.2 \%)$, respectively. Thirty-seven patients $(71.2 \%)$ had an AFP level $\leq 100 \mathrm{ng} / \mathrm{ml}$. A solitary nodule was present in $38(73.1 \%)$ patients and multiple nodules in $14(26.9 \%)$ patients. The mean tumor size in summation was $32.6 \pm 18.5 \mathrm{~mm}$ (range: $10-95 \mathrm{~mm}$ ).

Patients were followed up for a mean period of 11.2 \pm 4.7 months (range: 6-23 months; median: 9.8 months). All treatment-related adverse toxicities were classified as minor. Post embolization syndrome (fever, pain, and increased white blood cell count) developed in 7 patients without requiring extended stay or re-admission. Biloma occurred in 1 patient and was followed up without any treatment due to no symptom. One died from ischemic bowel disease at 9 months. Remaining 51 patients were alive at the time of analysis.

Total 151 computed tomography (CT) and 31 magnetic resonance (MR) images in 52 patients with hepatocellular carcinoma were reviewed to determine tumor response based on mRECIST. Figure 2 shows the Kaplan-Meier curve depicting the probability of maintaining complete response since the first selective TACE session. The cumulative complete response of the target lesions maintaining probabilities at 1, 4, 6, 9 and 12 months were $87 \%, 81 \%, 62 \%, 40 \%$ and $31 \%$, respectively.

Table 2 summarizes demographic characteristics and imaging data of patients by survival status at the end of the 6 th month. Patient with alpha fetoprotein level $<100 \mathrm{ng} / \mathrm{ml}$, less than two sessions before achieving complete response, a solitary nodule and with a tumor size in summation $\leq 30$ $\mathrm{mm}$ had a significantly higher odds of sustaining complete response at six months.

\section{Discussion}

Most of the patients in this series were males, had hepatitis B related cirrhosis and BCLC stage A with

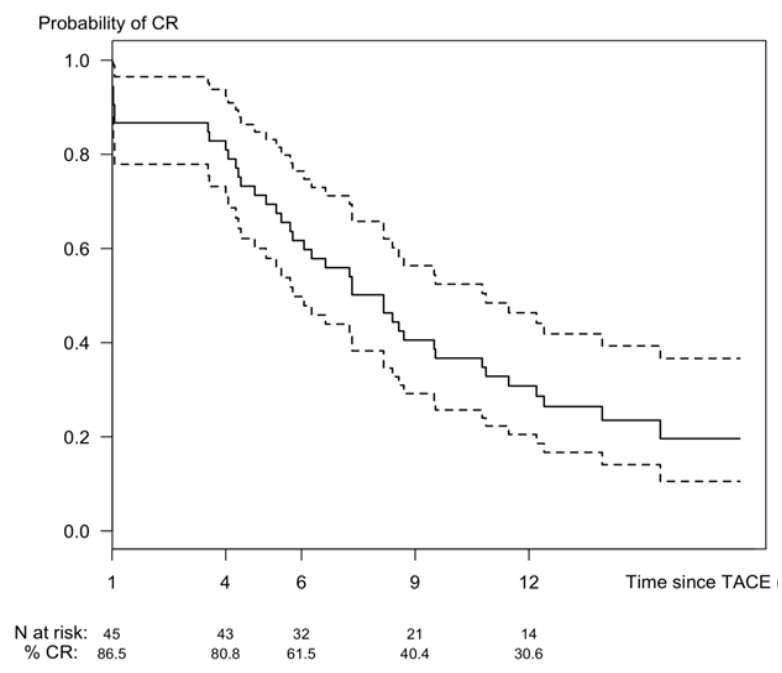

Figure 2. Kaplan-Meier Survival Curve Depicting the Probability of Sustained Complete Response for Patients with Hepatocellular Carcinoma Undergoing Selective TACE $(\mathrm{n}=52)$. 
Table 1. Demographic Characteristics and Clinical Profiles of Hepatocellular Carcinoma Patients before Undergoing Selective TACE $(\mathrm{n}=52)$

\begin{tabular}{|c|c|c|}
\hline Variable & Frequency & Percentage \\
\hline \multicolumn{3}{|l|}{ Age (years) } \\
\hline Mean (SD) & $64.0( \pm 9.6)$ & \\
\hline Range & $41-90$ & \\
\hline \multicolumn{3}{|l|}{ Sex } \\
\hline Male & 33 & 63.5 \\
\hline Female & 19 & 36.5 \\
\hline \multicolumn{3}{|l|}{ Etiology } \\
\hline HBV & 29 & 55.8 \\
\hline $\mathrm{HCV}$ & 7 & 13.5 \\
\hline Alcohol & 4 & 7.7 \\
\hline Hepatitis + Alcohol & 2 & 3.8 \\
\hline Other & 10 & 19.2 \\
\hline Child Pugh class & 42 & 80.8 \\
\hline A & 10 & 19.2 \\
\hline \multicolumn{3}{|l|}{$\mathrm{B}$} \\
\hline \multicolumn{3}{|c|}{ Alpha Fetoprotein (ng/ml) } \\
\hline$\leq 100$ & 37 & 71.2 \\
\hline$>100$ & 15 & 28.8 \\
\hline \multicolumn{3}{|l|}{ Albumin (g/dL) } \\
\hline$>3.5$ & 38 & 73.1 \\
\hline$\leq 3.5$ & 14 & 26.9 \\
\hline \multicolumn{3}{|l|}{ Total bilirubin (mg/dL) } \\
\hline$\leq 2$ & 49 & 94.2 \\
\hline$>2$ & 3 & 5.8 \\
\hline \multicolumn{3}{|l|}{ Prothrombin time (sec) } \\
\hline$>13.5$ & 27 & 51.9 \\
\hline$\leq 13.5$ & 25 & 48.1 \\
\hline \multicolumn{3}{|l|}{ Tumor burden } \\
\hline Solitary & 38 & 73.1 \\
\hline Multiple & 14 & 26.9 \\
\hline \multicolumn{3}{|c|}{ Tumor size in summation $(\mathrm{mm})$} \\
\hline$\leq 30$ & 27 & 51.9 \\
\hline $30-50$ & 18 & 34.6 \\
\hline$>50$ & 7 & 13.5 \\
\hline \multicolumn{3}{|l|}{ BCLC stage } \\
\hline A & 5 & 48.1 \\
\hline $\mathrm{B}$ & 19 & 36.5 \\
\hline $\mathrm{C}$ & 8 & 15.4 \\
\hline
\end{tabular}

BCLC, Barcelona Clinic Liver Cancer

normal range of albumin level, and low levels of AFP and total bilirubin before undergoing selective TACE. After performing the procedure, the cumulative complete response rate at 6 months was $62 \%$. The strongest predictor was number of TACE session $\leq 2$ times, and the weakest was tumor size in summation $\leq 30 \mathrm{~mm}$. Number of tumor nodules was significant in univariate analysis but not in multivariate logistic regression model.

TACE is the most common mode of treatment in Thailand because of a large number of patient presenting
Table 2. Comparison of Demographic and Clinical Factors and Results of Univariate Analysis among Patients who Sustained Complete Response at 6 Months since Undergoing Selective TACE Compared to Those who Did not

\begin{tabular}{|c|c|c|c|c|}
\hline Variables & $\begin{array}{c}\text { Sustained } \\
\text { CR } \\
(\mathrm{n}=32)\end{array}$ & $\begin{array}{c}\text { Did not } \\
\text { sustain CR } \\
\quad(\mathrm{n}=20)\end{array}$ & $\begin{array}{c}\text { Odds Ratio } \\
(95 \% \mathrm{CI})\end{array}$ & $P$ value \\
\hline \multicolumn{5}{|l|}{ Gender } \\
\hline Male & $20(62.5)$ & $13(65)$ & 1 & 0.855 \\
\hline Female & $12(37.5)$ & $7(35)$ & $1.1(0.35-3.57)$ & \\
\hline \multicolumn{5}{|l|}{ Age (years) } \\
\hline$\leq 65$ & $16(50)$ & $12(60)$ & $0.67(0.22-2.07)$ & 0.481 \\
\hline$>65$ & $16(50)$ & $8(40)$ & 1 & \\
\hline Etiology & & & & 0.522 \\
\hline Alcohol & $2(6.2)$ & $2(10)$ & 1 & \\
\hline HBV & $20(62.5)$ & $9(45)$ & $2.22(0.27-18.37)$ & \\
\hline $\mathrm{HCV}$ & $5(15.6)$ & $2(10)$ & $2.5(0.19-32.19)$ & \\
\hline $\begin{array}{l}\text { Hepatitis + } \\
\text { Alcohol }\end{array}$ & $1(3.1)$ & $1(5)$ & $1(0.03-29.81)$ & \\
\hline Others & $4(12.5)$ & $6(30)$ & $0.67(0.06-6.87)$ & \\
\hline \multicolumn{5}{|c|}{ Child-Pugh Class } \\
\hline A & $26(81.2)$ & $16(80)$ & $1.08(0.26-4.44)$ & 0.912 \\
\hline B & $6(18.8)$ & $4(20)$ & 1 & \\
\hline \multicolumn{5}{|c|}{ Alpha fetoprotein (ng/ml) } \\
\hline$\leq 100$ & $27(84.4)$ & $10(50)$ & $5.4(1.48-19.73)$ & $0.008^{*}$ \\
\hline$>100$ & $5(15.6)$ & $10(50)$ & 1 & \\
\hline \multicolumn{5}{|l|}{ Albumin } \\
\hline$\leq 3.5$ & $9(28.1)$ & $5(25)$ & 1 & 0.804 \\
\hline$>3.5$ & $23(71.9)$ & $15(75)$ & $0.85(0.24-3.04)$ & \\
\hline \multicolumn{5}{|l|}{ Total bilirubin } \\
\hline$>2$ & $1(3.1)$ & $2(10)$ & 1 & 0.309 \\
\hline$\leq 2$ & $31(96.9)$ & $18(90)$ & $3.44(0.29-40.71)$ & \\
\hline \multicolumn{5}{|c|}{ Prothrombin time } \\
\hline$>13.5$ & $16(50)$ & $11(55)$ & 1 & 0.725 \\
\hline$\leq 13.5$ & $16(50)$ & $9(45)$ & $1.22(0.4-3.75)$ & \\
\hline \multicolumn{5}{|c|}{ Number of sessions } \\
\hline$\leq 2$ & $31(96.9)$ & $16(80)$ & $7.75(0.8-75.23)$ & $0.045^{*}$ \\
\hline$>2$ & $1(3.1)$ & $4(20)$ & 1 & \\
\hline \multicolumn{5}{|c|}{ Number of tumor nodules } \\
\hline$>1$ & $4(12.5)$ & $10(50)$ & 1 & $0.003 *$ \\
\hline 1 & $28(87.5)$ & $10(50)$ & $7.00(1.79-27.44)$ & \\
\hline \multicolumn{5}{|c|}{ Tumor size in summation(mm) } \\
\hline$\leq 30$ & $21(65.6)$ & $6(30)$ & $4.45(1.34-14.83)$ & $0.011 *$ \\
\hline$>30$ & $11(34.4)$ & $14(70)$ & 1 & \\
\hline \multicolumn{5}{|c|}{ Lobar involvement } \\
\hline Unilobar & $31(96.9)$ & $17(85)$ & $5.47(0.53-56.75)$ & 0.122 \\
\hline Bilobar & $1(3.1)$ & $3(15)$ & 1 & \\
\hline \multicolumn{5}{|c|}{ Subcapsular location } \\
\hline Yes & $26(81.2)$ & $16(80)$ & 1 & 0.912 \\
\hline No & $6(18.8)$ & $4(20)$ & $0.92(0.23-3.78)$ & \\
\hline \multicolumn{5}{|c|}{ Portal vein thrombosis } \\
\hline Yes & $5(15.6)$ & $3(15)$ & 1 & 0.951 \\
\hline No & $27(84.4)$ & $17(85)$ & $0.95(0.2-4.51)$ & \\
\hline \multicolumn{5}{|c|}{ Near portal vein } \\
\hline Yes & $5(15.6)$ & $5(25)$ & 1 & 0.409 \\
\hline No & $27(84.4)$ & $15(75)$ & $1.8(0.45-7.23)$ & \\
\hline
\end{tabular}

*, Likelihood ratio test; CR, complete response. HBV, hepatitis B virus; $\mathrm{HCV}$, hepatitis $\mathrm{C}$ virus 
Table 3. Multivariate Logistic Regression Model Predicting Sustained Complete Response at 6 Months and Prognostic Factors in HCC Patients Undergoing Selective TACE

\begin{tabular}{lcc}
\hline Predictor & OR $(95 \% \mathrm{CI})$ & P-value* \\
\hline Alpha Fetoprotein $\leq 100 \mathrm{ng} / \mathrm{ml}$ & $5.4(1.48-19.73)$ & 0.018 \\
Tumor size in summation $\leq 30 \mathrm{~mm}$ & $4.45(1.34-14.83)$ & 0.031 \\
Number of TACE sessions $\leq 2$ & $7.75(0.80-75.23)$ & 0.032 \\
Unilobar involvement & $5.47(0.53-56.75)$ & 0.044 \\
\hline
\end{tabular}

*, Likelihood ratio test; OR, Odds ratio; CI, Confidence interval

with large and multifocal HCCs. It was accounted $13-41 \%$ of total treatment of HCC in Thailand (Chonprasertsuk et al., 2017). Therefore, our study used the tumor size $\leq 7 \mathrm{~cm}$, and number of distinct hypervascular tumors $\leq 5$ to be the inclusion criteria. In contrary with the previous studies from Japan (Miyayama et al., 2007; Matsui et al., 2010) included patients with HCC who had fewer than three hypervascular tumors smaller than $5 \mathrm{~cm}$ in diameter. Moreover, there are some differences in the background of patients. Chronic HBV infection is the most common cause of HCC in our study, whereas HCV infection is the major risk factor in Japan study (Miyayama et al., 2007).

Selective TACE, although incurring increased costs and procedural time for catheterization, leads to better clinical outcomes when compared with non-selective TACE (Yamakado et al., 2012). Lipiodol or iodized oil in TACE can deeply pass into surrounding portal venules and hepatic sinusoids through peribiliary plexus resulting in low rates of local tumor recurrence (Miyayama et al., 2007). In our study, the changes in complete response rates over time were similar to those in other previous studies from Japan (Miyayama et al., 2007; Matsui et al., 1993; Takayasu et al., 2001; Miyayama et al., 2009; Matsui et al., 2010) and were better than the European randomized controlled trials on non-selective TACE by Llovet et al., (2002), which yielded partial response rates of $15-55 \%$. Selective TACE can limit the damage to liver parachyma at the subsegment level, thus reducing the complications. Post embolization syndrome, for example, could be reduced from $60-80 \%$ in two previous reports (Raoul et al., 2014; Ebied et al., 2014) to $13.5 \%$ in our study. Hepatic failure from liver ischemia was also reduced from $49 \%$ in a previous study (Ebied et al., 2014) to $0 \%$ in our study.

Assessment at 1-month follow up may be too early to determine whether patients achieve complete response due to non-specific Lipiodol accumulation surrounding the tumor, and washout of Lipiodol cannot be evaluated by computed tomography scan 4 weeks after the procedure (Kim et al., 2015). Therefore we used a sustained CR at 6-months follow up for recognition of predictive factors.

Serum AFP at the time of TACE is a predictor for maintaining complete response at six months. AFP plays important roles in both immune system inhibition and encouraging cancer cell growth. High serum AFP showed a poorer differentiation grade of $\mathrm{HCC}$ and needs to be closely followed up with consideration of additional treatments (Okuda et al., 2001; Veltri et al, 2006; Evdokimova et al., 2007). On the other hand, low serum AFP may indicate a less aggressive tumor and thus lower rate of tumor recurrence.
Difficulty in performing TACE varies case by case, depending on various factors such as tumor size, number of nodules, location, and spreading pattern of the tumor. Difficult cases are more likely to require more sessions of TACE to achieve complete response. The non-cancerous liver tissues are also more damaged by multiple sessions of TACE. Two consecutive poor responses to TACE was a criterion for TACE failure/refractoriness (Kudo et al., 2014; Raoul et al., 2014). These and other previous findings related to multiple TACE sessions (Kim et al., 2015 ) could explain why the number of TACE sessions is a predictive factor for sustained CR in our results.

Larger tumors usually have more satellite lesions or daughter nodules making it difficult for selective TACE to achieve completely response. Smaller sized tumors, especially those less than $30 \mathrm{~mm}$, had a high complete response rate, as a result previously reported by Ebied et al., (2003). In our study, tumor size in summation $\leq 30 \mathrm{~mm}$ was a predictive factor for sustained complete response at six months, a result similar to the study by Golfieri et al., (2013) who reported that tumors $\leq 50 \mathrm{~mm}$ achieved the best response to selective TACE. For the same reason, unilobar tumors can be treated effectively with selective TACE by occluding tumor supplying arteries those that are not relatively complex compared with multiple and bilobar tumors.

This study was limited by its retrospective nature. The number of patients in this series was also relatively small and the follow up time was relatively short. The technical factors in TACE such as grading of portal vein visualization or safety margin of lipiodol accumulation were not assessed in this study. The study population of this study is quite narrow window of TACE indication, so these selected patient group has relative high tumor response rate.

In conclusion, selective TACE has a lower complication rate, has a good therapeutic results and can sustained complete response in selected HCC patients. Serum $\mathrm{AFP} \leq 100 \mathrm{ng} / \mathrm{ml}$, a few sessions of selective TACE, tumor size in summation $\leq 30 \mathrm{~mm}$ and unilobar involvement were favorable predictive factors for sustained complete response of HCC patients.

\section{Acknowledgements}

The authors thank Assoc. Prof. Teerha Piratvisuth, for guidance on the frame of analysis and in preparation of this manuscript.

\section{References}

Arii S, Sata M, Sakamoto M, et al (2010). Management of hepatocellular carcinoma: Report of Consensus Meeting in the 45th Annual Meeting of the Japan Society of Hepatology (2009). Hepatol Res, 40, 667-85.

Bosch FX, Ribes J, Borràs J (1999). Epidemiology of primary liver cancer. Semin Liver Dis, 19, 271-85.

Bruix J, Llovet JM (2002). Prognostic prediction and treatment strategy in hepatocellular carcinoma. Hepatology, 35, 519-24.

Bruix J, Sherman M (2011). American association for the study of liver diseases. Management of hepatocellular carcinoma:

Asian Pacific Journal of Cancer Prevention, Vol 193549 
an update. Hepatology, 53, 1020-2.

Bruix J, Sherman M, Llovet JM, et al (2001). Clinical management of hepatocellular carcinoma. Conclusions of the Barcelona-2000 EASL conference. European Association for the Study of the Liver. J Hepatol, 35, 421-30.

Chonprasertsuk S, Vilaichone R-K (2017). Epidemiology and treatment of hepatocellular carcinoma in Thailand. Jpn J Clin Oncol, 47, 294-7.

Ebied OM, Federle MP, Carr BI, et al (2003). Evaluation of responses to chemoembolization in patients with unresectable hepatocellular carcinoma. Cancer, 97, 1042-50.

Evdokimova VN, Liu Y, Potter DM, Butterfield LH (2007). AFP-specific CD4+ helper T-cell responses in healthy donors and HCC patients. J Immunother, 30, 425-37.

Golfieri R, Renzulli M, Mosconi C, et al (2013). Hepatocellular carcinoma responding to superselective transarterial chemoembolization: an issue of nodule dimension?. J Vasc Interv Radiol, 24, 509-17.

Iwamoto S, Sanefuji H, Okuda K (2003). Angiographic subsegmentectomy for the treatment of patients with small hepatocellular carcinoma. Cancer, 97, 1051-6.

Jeong SO, Kim EB, Jeong SW, et al (2017). Predictive factors for complete response and recurrence after transarterial chemoembolization in Hepatocellular Carcinoma. Gut Liver, 11, 409-16.

Kim BK, Kim SU, Kim KA, et al (2015). Complete response at first chemoembolization is still the most robust predictor for favorable outcome in hepatocellular carcinoma. J Hepatol, 62, 1304-10.

Kudo M, Matsui O, Izumi N, et al (2014). Transarterial chemoembolization failure/refractoriness: JSH-LCSGJ criteria 2014 update. Oncology, 87, 22-31.

Lencioni R (2012). Chemoembolization for hepatocellular carcinoma. Semin Oncol, 39, 503-9.

Lencioni R, Llovet JM (2010). Modified RECIST (mRECIST) assessment for hepatocellular carcinoma. Semin Liver Dis, 30, 52-60.

Llovet JM, Brú C, Bruix J (1999). Prognosis of hepatocellular carcinoma: the BCLC staging classification. Semin Liver Dis, 19, 329-38.

Llovet JM, Di Bisceglie AM, Bruix J, et al (2008). Design and endpoints of clinical trials in hepatocellular carcinoma. J Natl Cancer Inst, 100, 698-711.

Llovet JM, Real MI, Montaña X, et al (2002). Arterial embolisation or chemoembolisation versus symptomatic treatment in patients with unresectable hepatocellular carcinoma: a randomised controlled trial. Lancet, 359, 1734-9.

Matsui O, Kadoya M, Yoshikawa J, et al (1993). Small hepatocellular carcinoma: treatment with subsegmental transcatheter arterial embolization. Radiology, 188, 79-83.

Matsui O, Miyayama S, Sanada J, et al (2010). Interventional oncology: new options for interstitial treatments and intravascular approaches: superselective TACE using iodized oil for HCC: rationale, technique and outcome. $J$ Hepatobiliary Pancreat Sci, 17, 407-9.

Miyayama S, Matsui O, Yamashiro M, et al (2007). Ultraselective transcatheter arterial chemoembolization with a $2-\mathrm{f}$ tip microcatheter for small hepatocellular carcinomas: relationship between local tumor recurrence and visualization of the portal vein with iodized oil. J Vasc Interv Radiol, 18, 365-76.

Miyayama S, Mitsui T, Zen Y, et al (2009). Histopathological findings after ultraselective transcatheter arterial chemoembolization for hepatocellular carcinoma. Hepatol Res, 39, 374-81.

Okuda H, Nakanishi T, Takatsu K, et al (2001). Comparison of clinicopathological features of patients with hepatocellular carcinoma seropositive for alpha-fetoprotein alone and those seropositive for des-gamma-carboxy prothrombin alone. J Gastroenterol Hepatol, 16, 1290-6.

Pugh RN, Murray-Lyon IM, Dawson JL, Pietroni MC, Williams R (1973). Transection of the oesophagus for bleeding oesophageal varices. Br J Surg, 60, 646-9.

Raoul J-L, Gilabert M, Piana G (2014). How to define transarterial chemoembolization failure or refractoriness: A European Perspective. Liver Cancer, 3, 119-24.

Shin SW (2009). The current practice of transarterial chemoembolization for the treatment of Hepatocellular Carcinoma. Korean J Radiol, 10, 425-34.

Takayasu K, Muramatsu Y, Maeda T, et al (2001). Targeted transarterial oily chemoembolization for small foci of hepatocellular carcinoma using a unified helical CT and angiography system: analysis of factors affecting local recurrence and survival rates. AJR Am J Roentgenol, 176, 681-8.

Torre LA, Bray F, Siegel RL, et al (2015). Global cancer statistics. CA Cancer J Clin, 65, 87-108.

Trinchet JC, Beaugrand M (1997). Treatment of hepatocellular carcinoma in patients with cirrhosis. J Hepatol, 27, 756-65.

Veltri A, Moretto P, Doriguzzi A, et al (2006). Radiofrequency thermal ablation (RFA) after transarterial chemoembolization (TACE) as a combined therapy for unresectable non-early hepatocellular carcinoma (HCC). Eur Radiol, 16, 661-9.

Wigmore SJ, Redhead DN, Thomson BNJ, et al (2003). Postchemoembolisation syndrome - tumour necrosis or hepatocyte injury?. Br J Cancer, 89, 1423-7.

Yamakado K, Miyayama S, Hirota S, et al (2012). Hepatic arterial embolization for unresectable hepatocellular carcinomas: do technical factors affect prognosis?. Jpn J Radiol, 30, 560-6.

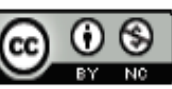

This work is licensed under a Creative Commons AttributionNon Commercial 4.0 International License. 